\title{
Enhancement of plasticity in Ti-based metallic glass matrix composites by controlling characteristic and volume fraction of primary phase
}

\author{
K.R. Lim \\ Center for Non-Crystalline Materials, Department of Materials Science and Engineering, \\ Yonsei University, Seodaemun-Ku, Seoul 120-749, South Korea \\ J.H. Na \\ California Institute of Technology, Division of Engineering and Applied Science, \\ Pasadena, California 91125 \\ J.M. Park \\ Center for Non-Crystalline Materials, Department of Materials Science and Engineering, \\ Yonsei University, Seodaemun-Ku, Seoul 120-749, South Korea; and IFW Dresden, \\ Institute for Complex Materials, D-01171 Dresden, Germany \\ W.T. Kim \\ IT Division, Cheongju University, Cheongju 360-764, South Korea \\ D.H. Kim ${ }^{\text {a) }}$ \\ Center for Non-Crystalline Materials, Department of Materials Science and Engineering, \\ Yonsei University, Seodaemun-Ku, Seoul 120-749, South Korea
}

(Received 28 April 2010; accepted 28 July 2010)

In this study, Ti-based metallic glass matrix composites with high plasticity have been developed by controlling characteristic and volume fraction of primary phase embedded in the glass matrix. By careful alloy design procedure, the compositions of $\beta /$ glass phases, which are in metastable equilibrium have been properly selected, therefore the mechanical properties can be tailored by selecting the alloy compositions between the composition of $\beta$ and glass phases. The relation between the compressive yield strength and volume fraction of $\beta$ phase is well described using the rule of mixtures.

\section{INTRODUCTION}

A number of bulk metallic glasses (BMGs) have been developed as potential engineering materials having unique properties due to the random atomic configurations. The BMGs exhibit promising properties such as high yield strength and hardness, large elastic limit, and good corrosion resistance. ${ }^{1}$ Despite these promising properties, the application of the BMGs as a structural material is limited. One of the major drawbacks of the BMGs is their limited plasticity, compared with currently used crystalline alloys. To improve the plasticity of BMGs, a great amount of research has been performed. The main idea for enhancement of plasticity is to introduce some inhomogeniety, ranging atomic scale to micrometer $(\mu \mathrm{m})$ scale in BMG matrix with an intention either to enhance shear band nucleation or to block shear band propagation. One of the ways to introduce inhomogeniety is to develop metallic glass matrix composites (MGMCs) consisting of crystalline phases distributed in the BMG matrix. ${ }^{2}$ The MGMCs have been found to exhibit enhanced plasticity, which is not gener-

\footnotetext{
a) Address all correspondence to this author.

e-mail: dohkim@yonsei.ac.kr

DOI: 10.1557/JMR.2010.0277
}

ally observed in monolithic BMGs. ${ }^{3,4}$ Such an enhancement of plasticity stems possibly from the formation of multiple shear bands initiated at the interface between the reinforcing agent and the metallic glass matrix, and their confinement in MGMCs. ${ }^{5-8}$

From this point of view, recently, many researchers have investigated extensively the development of MGMCs mainly in Zr-based metallic glasses. ${ }^{9,10}$ However, to extend the application fields of the BMGs, more attention should be drawn to the development of BMGs based on common metals such as $\mathrm{Ni}, \mathrm{Cu}, \mathrm{Fe}$, and $\mathrm{Ti}^{11}{ }^{11}$ In contrast to Zr-based MGMCs, Ti-based MGMCs have low density almost matching that of commercial Ti-alloys. In particular, $\mathrm{Ti}-\mathrm{Zr}-\mathrm{Ni}-\mathrm{Cu}-\mathrm{Be}$ BMGs exhibiting high glassforming ability (GFA) have been reported to show some plasticity even in as-cast (arc-melted) ingots and in assuction-cast specimens. ${ }^{12,13} \mathrm{Ti}_{40} \mathrm{Zr}_{25} \mathrm{Ni}_{3} \mathrm{Cu}_{12} \mathrm{Be}_{20}$ BMG has been reported to exhibit a high GFA enabling fabrication of a fully glassy rod up to $14 \mathrm{~mm}$ diameter and a reasonably good mechanical property (ultimate compressive strength: $1780 \mathrm{MPa}$, plastic strain: $2-5 \%) .{ }^{13} \mathrm{On}$ the basis of the previous result, ${ }^{13}$ the composition of $\mathrm{Ti}_{40} \mathrm{Zr}_{25} \mathrm{Ni}_{4.6} \mathrm{Cu}_{10.4} \mathrm{Be}_{20}$ was selected as a starting alloy composition in this study. $\mathrm{Nb}$ is then selected as an alloying element since it is known as one of the alloying 
elements that strongly stabilize the formation of the $\beta$ phase. ${ }^{14,15}$ Furthermore, it is known that shear modulus (G) of body-centered-cubic (bcc) Ti-based solid solutions dramatically lower with $\mathrm{Nb}$ or $\mathrm{V}$ addition. ${ }^{16}$ It is considered that shear band extension is expected to be strongly attracted to the crystalline inclusion, which exhibits lower $\mathrm{G}$ than that of the glass matrix, therefore the plasticity and fracture toughness of the composites would be improved. ${ }^{17}$ The main aim of this study is to find out the compositions of the $\beta$ and glass phases that are in pseudobinary quasi-equilibrium state.

As a result, by a careful alloy design procedure, we have designed a $\beta$ phase-reinforced Ti-based BMG composite in which the relative volume fraction of two phases can be controlled by selecting proper alloy composition between the compositions of crystalline $\beta$ and glassy phases that are in quasi-equilibrium. Therefore, it is possible to tailor the mechanical properties of Ti-based MGMC by control of the relative volume fraction of the $\beta$ and glassy phases, as previously reported in $\mathrm{Zr}$-based MGMC. $^{14}$

\section{EXPERIMENTAL}

Ingots $(10 \mathrm{~g})$ with nominal compositions were prepared by arc-melting under an Ar atmosphere. Raw materials with a purity ranging from $99.9 \%$ to $99.99 \%$ were used for the arc-melting process. For addition of $\mathrm{Be}, \mathrm{Be}-\mathrm{Cu}-\mathrm{Ni}$ master alloy was used. Each alloy was remelted several times to obtain a homogeneous composition distribution. Rod specimens with a diameter of $5 \mathrm{~mm}$ were produced by a suction casting method. Structural characterization was performed by using x-ray diffractometry (XRD) with monochromatic $\mathrm{Cu} \mathrm{K}$ 年 radiation (Rigaku, RINT2200, Tokyo, Japan). A transmission electron microscope (TEM; JEOL, 2010F, Tokyo, Japan) equipped with energy dispersive spectrometer (EDS; Oxford Instruments, INCA $\mathrm{x}$-act 51-ADD0069, Oxfordshire, UK) was used for phase analysis and microcompositional analysis of constituent phases. The samples for TEM imaging were carefully prepared to avoid any structural changes by using an ion milling system equipped with cold stage. Scanning electron microscopy (SEM; JEOL, JSM-7600F) was used for characterization of the as-cast microstructures. The volume fraction of the phase was measured from the SEM image using image analyzer (IMT i-solution Inc., IMT i-solution version 6.5, Vancouver, Canada). Mechanical properties of the samples were measured at room temperature under a compressive mode with a strain rate of $1 \times$ $10^{-4} \mathrm{~s}^{-1}$ using an Instron-type machine (Hounsfield Test Equipment, H25KT, Salfords, UK). For the compression test, rectangular MGMC samples with dimension of $2.5 \times$ $2.5 \times 5 \mathrm{~mm}^{3}$ were prepared from suction cast rod specimens. There was no noticeable structural inhomogeneity along the length of the sample, but there was a structural inhomogeneity, i.e., a difference in dendrite size, along the radius of the sample due to the cooling rate difference. To avoid the structural inhomogeneity in the sample for the compression test, only the central portion of the cast rod was used after cutting off $\sim 10 \mathrm{~mm}$ from both the top and bottom of the cast rod along the length direction. Inside the sample structural heterogeneity was negligible, because we cut the outer shell of the cast rods when we prepare the samples for compression tests.

\section{RESULTS AND DISCUSSION}

\section{A. Effect of $\mathrm{Nb}$ addition}

To investigate the effect of $\mathrm{Nb}$ addition on the phase formation in $\mathrm{Ti}_{40} \mathrm{Zr}_{25} \mathrm{Ni}_{4.6} \mathrm{Cu}_{10.4} \mathrm{Be}_{20}$ alloy, three alloys with the compositions of $\left(\mathrm{Ti}_{40} \mathrm{Zr}_{25} \mathrm{Ni}_{4.6} \mathrm{Cu}_{10.4} \mathrm{Be}_{20}\right)_{100-x}$ $\mathrm{Nb}_{x}(x=0,7,14$, referred to as LN0, LN7, and LN14, respectively, hereafter) were suction-cast into $\mathrm{Cu}$-mold with the size of $5 \mathrm{~mm}$ diameter. The rod diameter was selected after some preliminary experiments to obtain a cooling rate suitable for the formation of glass and crystalline phases simultaneously (i.e., faster than the critical cooling rate for the glass formation and slow enough for the formation of $\beta$ phase during cooling). Figure 1 shows typical backscattered electron images obtained from the as-cast LN0, LN7, and LN14 alloy rod specimens. Both LN0 and LN14 specimens show composites microstructure, consisted of uniformly distributed crystalline dendrites embedded in a glass matrix. The volume fraction of the dendrite phase was estimated to be $\sim 45 \%$ for the LN0 specimen and $\sim 28 \%$ for the LN14 specimen. Figure 2 shows XRD patterns obtained from the LNO, LN7, and LN14 specimens, respectively. The XRD trace from the LN0 specimen exhibited a broad halo pattern peak at $\sim 39^{\circ}$ superimposed with sharp diffraction peaks corresponding to crystalline phases. The diffraction peaks could be analyzed into a mixture of bcc $\beta$ and orthorhombic $\alpha^{\prime \prime}$ martensite phases. The XRD trace from the LN7 specimen exhibited a broad halo pattern, characteristic of the amorphous phase, indicating a formation of fully amorphous phase during solidification into a rod $5 \mathrm{~mm}$ in diameter. The XRD trace from the LN14 specimen exhibited a broad halo pattern peak at $\sim 39^{\circ}$ superimposed with sharp diffraction peaks corresponding to the bcc $\beta$ phase. With increasing of $\mathrm{Nb}$ content in the LN0 alloy, GFA improved enabling formation of a fully

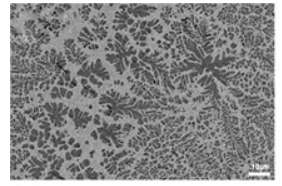

(a)



(b)

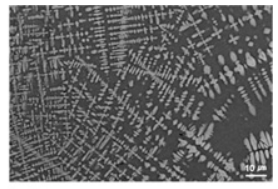

(c)
FIG. 1. SEM backscattered images of as-cast (a) $\mathrm{Ti}_{40} \mathrm{Zr}_{25} \mathrm{Ni}_{4.6}$ $\mathrm{Cu}_{10.4} \mathrm{Be}_{20}$ (LNO), (b) $\left(\mathrm{Ti}_{40} \mathrm{Zr}_{25} \mathrm{Ni}_{4.6} \mathrm{Cu}_{10.4} \mathrm{Be}_{20}\right)_{93} \mathrm{Nb}_{7}$ (LN7), and (c) $\left(\mathrm{Ti}_{40} \mathrm{Zr}_{25} \mathrm{Ni}_{4.6} \mathrm{Cu}_{10.4} \mathrm{Be}_{20}\right)_{86} \mathrm{Nb}_{14}$ (LN14) alloys. 


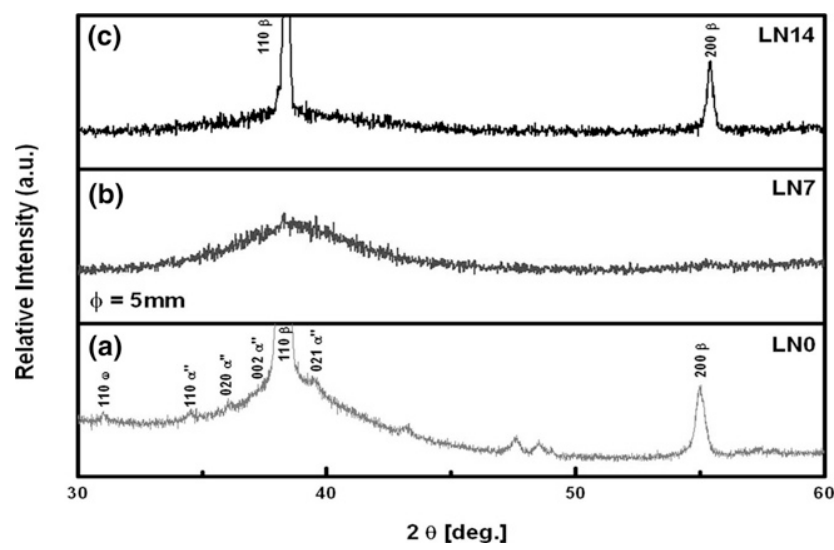

FIG. 2. XRD patterns of as-cast (a) LNO, (b) LN7, and (c) LN14 rods with a $5 \mathrm{~mm}$ diameter.

glassy rod with $5 \mathrm{~mm}$ diameter when the $\mathrm{Nb}$ amount was $x=7$ at. $\%$ (LN7 alloy). ${ }^{18}$ However, with further increasing $\mathrm{Nb}$ content, the GFA was deteriorated. Interestingly, when the $\mathrm{Nb}$ content increased up to 14 at.\% (LN14 alloy), two-phase microstructure again appeared, as can be seen in Fig. 1(c).

Here, one can notice there are two major differences between the microstructures shown in Figs. 1(a) and 1(c): (i) The morphology of the dendritic phase in the LN0 and LN14 alloys are significantly different. The dendritic bcc $\beta$ phase in the LN14 alloy exhibits a stronger tendency for preferential growth than that in the LNO alloy, suggesting that the dendritic phase in the LN14 alloy formed at a much higher temperature than that in the LN0 alloy, thereby enabling an easier growth of dendrite in a preferential direction. Such a high temperature for the formation of the dendritic phase in the $\mathrm{Nb}$ containing alloy is attributed to the higher content of $\mathrm{Nb}$ in the dendritic phase. Table I lists the EDS analysis results of dendritic and glass phases in the LN0 and LN14 alloys, revealing that the dendritic phase contains a much higher amount of $\mathrm{Nb}$ than the glass matrix in the LN14 alloy. (Here, we assumed that there is no Be content in the dendritic phase.) It is considered that such a higher $\mathrm{Nb}$ content in the bcc $\beta$ phase favors the preferential growth of the dendrites; (ii) the contrast of the $\beta$ and glassy phases are reversed with the addition of $\mathrm{Nb}$ in the LNO alloy, as described previously. The reversal of the contrast in the $\beta$ and glassy phases is attributed to the compositional change in the dendritic and glassy phases with the addition of $\mathrm{Nb}$, as shown in the EDS analysis results (Table I); and (iii) the dendrite phases in the LNO and LN14 alloys have different structure as shown in XRD and TEM results (Figs. 2-4). In the dendrite phase of the LN0 and LN14 alloys, partial phase transformation of the $\beta$ phase occurred during cooling, but in the different route, i.e., $\beta \rightarrow \alpha^{\prime \prime}$ martensite transformation in LNO alloy and $\beta \rightarrow \omega$ transition in LN14 alloy, which will be explained in detail from the TEM results below.
TABLE I. The EDS analysis results of amorphous and dendritic phases in LN0, LN14, and DN14 alloys.

\begin{tabular}{lcrrrrc}
\hline \hline & $\mathrm{Ti}$ & $\mathrm{Zr}$ & $\mathrm{Nb}$ & $\mathrm{Ni}$ & $\mathrm{Cu}$ & $\mathrm{Be}$ \\
\hline Matrix of LN0 alloy & 20.8 & 24.6 & $\ldots$ & 4.7 & 12.2 & 37.7 \\
Dendrite of LN0 alloy & 60.9 & 31.7 & $\ldots$ & 1.1 & 6.4 & $\ldots$ \\
Matrix of LN14 alloy & 25.2 & 27.1 & 4.8 & 5.7 & 12.6 & 24.6 \\
Dendrite of LN14 alloy & 45.5 & 9.0 & 42.8 & $\ldots$ & 2.7 & $\ldots$ \\
Matrix of DN14 alloy & 28.0 & 24.3 & 4.1 & 5.7 & 13.2 & 24.6 \\
Dendrite of DN14 alloy & 50.3 & 12.9 & 32.0 & $\ldots$ & 4.7 & $\ldots$ \\
\hline \hline
\end{tabular}

The structure of the dendrite phase was further examined by TEM (Figs. 3 and 4). Figure 3(a) shows a brightfield TEM image obtained from the LNO specimen, showing crystalline phase embedded in an amorphous matrix. The halo rings in Fig. 3(b) show the existence of the amorphous phase in the matrix, as marked by the arrow in Fig. 3(a). In the dendrite region, it can be recognized there are two types of regions, as marked by the circle and square. Figures 3(c) and 3(d) show a selected-area diffraction (SAD) pattern taken from the region marked by the circle in Fig. 3(a), and a schematically indexed diffraction pattern [[1 111] zone of the bcc $\beta$ phase (S.G.: $\operatorname{im} \overline{3} m$ )], respectively, confirming that there is a region of bcc $\beta$ phase in the dendrite phase. On the other hand, Fig. 3(e) shows the magnified view of the region marked as a square in Fig. 3(a). Figures 3(f) and 3(g) show an SAD pattern taken from the region shown in Fig. 3(e), and schematically indexed diffraction pattern $[[10 \overline{1}]$ zone of the orthorhombic $\alpha^{\prime \prime}$ martensite phase (S.G.: $\mathrm{Cmcm}$ )]. In particular, the $\alpha^{\prime \prime}$ martensite phase was present on the form of $(111) \alpha^{\prime \prime}$ twins, as can be seen from the bright-field TEM image [Fig. 3(e)] and SAD pattern [Figs. 3(f) and 3(g)]. The TEM analysis in Fig. 3 indicates that the dendrite phase in the LNO specimen consists of a mixture of bcc $\beta$ and orthorhombic $\alpha^{\prime \prime}$ martensite phases, which has been often observed in $\beta$-Ti-type alloys. ${ }^{19,20}$ The TEM result in Fig. 3 is in agreement with the XRD result shown in Fig. 2(a). The formation of the $\alpha^{\prime \prime}$ phase clearly indicates that partial martensite transformation took place in solid state during cooling after primary solidification into a $\beta$ phase.

Figure 4(a) shows a bright-field TEM image obtained from the LN14 specimen, confirming that the crystalline phase is embedded in an amorphous matrix. The SAD pattern in Fig. 4(b) taken from the region marked by an arrow consisted of diffuse halo rings, confirming an amorphous structure. Figure 4(c) shows the magnified image of the crystalline dendrite phase. Figures 4(d) and 4(e) show an SAD pattern taken from the region marked by a circle in Fig. 4(c), and schematically indexed diffraction pattern. Figure 4(e) shows that the SAD pattern in Fig. 4(d) consisted of superimposed [011] zone of the bcc $\beta$ phase and $[1 \overline{2} 10]$ zone of the hexagonal $\omega$ phase (S.G.: $P 6_{3} /$ $m m c$ ), exhibiting an orientation relationship; $[0 \overline{1} 1]_{\beta} / /$ $[1 \overline{2} 10]_{\omega}$ and $(211)_{\beta} / /(\overline{1} 010)_{\omega}$. The TEM result in Fig. 4 

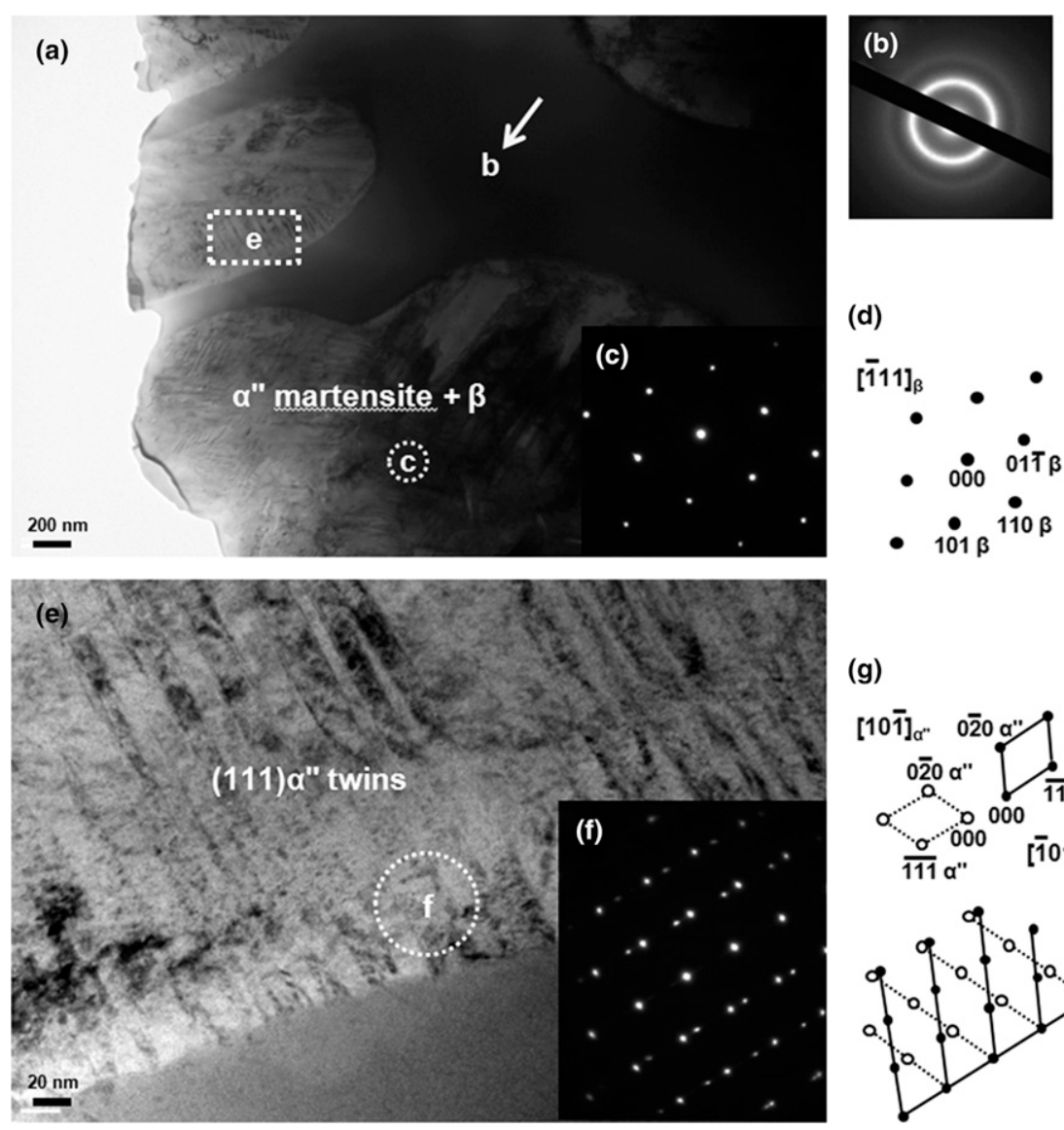

\section{(g)}

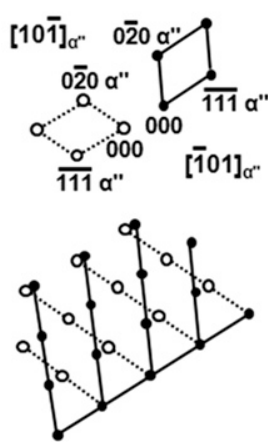

FIG. 3. TEM micrographs of as-cast (a) $\mathrm{Ti}_{40} \mathrm{Zr}_{25} \mathrm{Ni}_{4.6} \mathrm{Cu}_{10.4} \mathrm{Be}_{20}$ (LNO) alloy and corresponding SAD patterns taken from (b) the matrix and (c) dendrite region. (e) Magnified image taken from one $\alpha^{\prime \prime}$ martensite region in the dendrite phase including (111) $\alpha^{\prime \prime}$ twins. (d) and (g) are key diagrams of (c) and (f).

confirms that the dendrite phase in the LN14 alloy consists of a mixture of bcc $\beta$ and lamellar-type hexagonal $\omega$ (small-volume fraction) phases. The presence of the $\omega$ phase was not detected in the XRD trace [Fig. 2(c)] due to a small volume fraction of the $\omega$ phase. Indeed, the hexagonal $\omega$ phase has been reported to be occasionally observed in $\mathrm{Ti}-\mathrm{Nb}$ alloys. ${ }^{21,22}$ Again, the presence of $\omega$ phase clearly indicates a solid state transformation occurred during cooling. However, due to the addition of $\mathrm{Nb}$, which is known to be a $\beta$ stabilizing element, it is considered that $\alpha^{\prime \prime}$ martensite transformation is suppressed and $\omega$ phase transition is activated during the quench.

To examine the mechanical properties of Ti-based MGMCs, rod specimens with diameter of $5 \mathrm{~mm}$ were machined into the rectangular type samples having dimension of $2.5 \times 2.5 \times 5 \mathrm{~mm}^{3}$ (Fig. 5). Figure 5(a) shows typical compressive stress-strain curves at room temperature obtained from the as-cast LN0, LN7, and LN14 specimens. The three alloys exhibited nearly the same level of compressive fracture strength, i.e., $\sim 1800 \mathrm{MPa}$. The LN7 alloy consisted of a monolithic glassy phase and exhibited little plasticity. LNO and LN14 alloys exhibited a different level of plasticity, although they exhibit MGMC structure that consisted of dendrite $\beta$ phase embedded in a glassy matrix. The LN0 alloy exhibited very little plasticity, while the LN14 alloy exhibited a significantly enhanced plasticity, $\sim 22 \%$ total compressive strain including $\sim 20 \%$ plastic strain. To investigate the possible reason for the different level of plasticity in the $\beta$-glass two-phase microstructure, two alloys with the composition of dendrite ( $\mathrm{Ti}_{60.9} \mathrm{Zr}_{31.7} \mathrm{Ni}_{1.1} \mathrm{Cu}_{6.4}$ and $\mathrm{Ti}_{45.5} \mathrm{Zr}_{9.0} \mathrm{Nb}_{42.8} \mathrm{Cu}_{2.7}$ as listed in Table I) in the LN0 and LN14 alloys were suction-cast into a 5-mm-diameter rod for the compression test. The result of the compression test is shown in Fig. 5(b). Even though the two $\beta$ phase alloys exhibited nearly the same level of yield strength $(\sim 930 \mathrm{MPa})$, their plastic deformation behavior was significantly different from each other. The $\beta$-phase alloy with the composition of the dendrite in the LN14 alloy containing 14 at.\% Nb showed large elongation to failure ( $>40 \%$ ). The $\beta$ phase with the composition of the dendrite in the LNO alloy showed more pronounced work-hardening behavior than the previous alloy, i.e., higher fracture strength of $\sim 1530 \mathrm{GPa}$, but much lower elongation to failure $(\sim 7 \%)$. Therefore, it is considered that higher content of $\mathrm{Nb}$ in the $\beta$ phase makes the $\beta$ phase more stable preventing martensite transformation, therefore it provides a more ductile nature, resulting in significantly enhanced plasticity in the LN14 alloy. 

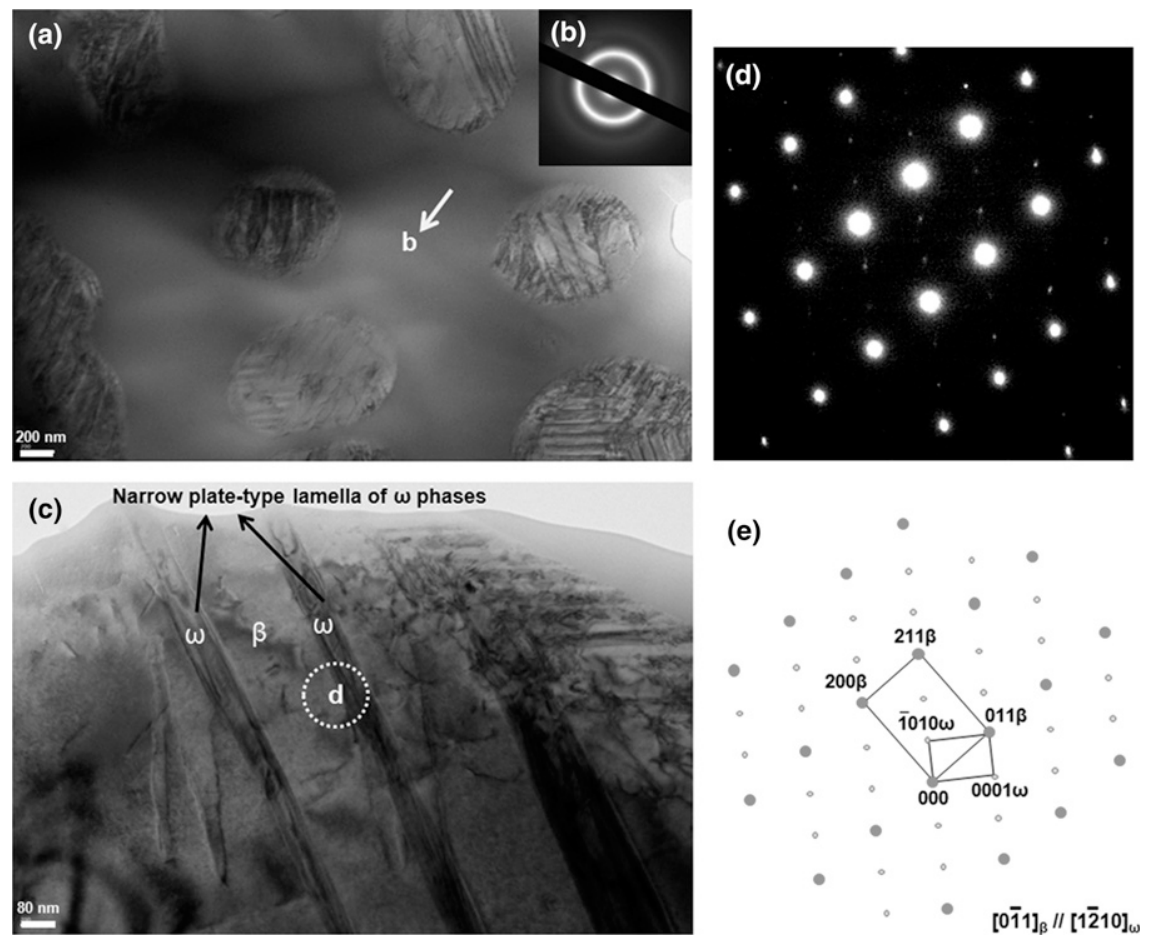

FIG. 4. TEM micrographs of as-cast (a) $\left(\mathrm{Ti}_{40} \mathrm{Zr}_{25} \mathrm{Ni}_{4.6} \mathrm{Cu}_{10.4} \mathrm{Be}_{20}\right)_{86} \mathrm{Nb}_{14}$ (LN14) alloy with (b) the corresponding SAD pattern inserted (c) Magnified image taken from one dendrite region including narrow plates of $\omega$ phases and (d) the corresponding SAD pattern. (e) Key diagram of (d) exhibiting twin lamella between bcc $\beta$ and metastable $\omega$ phases.

(a)

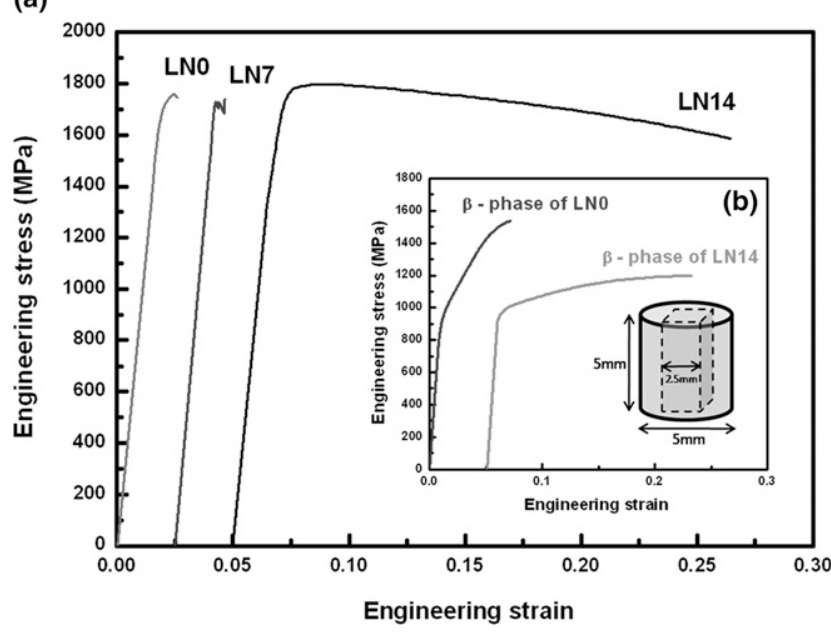

FIG. 5. (a) Compressive engineering stress-strain curves at room temperature for the machined LNO, LN7, and LN14 specimens. (b) Compressive engineering stress-strain curves at room temperature for the machined $\beta$-phase specimens.

\section{B. Pseudobinary quasi-equilibrium between $\beta$ and glass phases}

To optimize quantitatively the volume fraction of $\beta$ phase for the enhancement of plasticity in the $\mathrm{Ti}-\mathrm{Zr}-$ $\mathrm{Ni}-\mathrm{Cu}-\mathrm{Be}-\mathrm{Nb}$ system, we have performed the alloy design procedure starting from the LN14 alloy, which showed a better combination of strength and ductility than the LN0 and LN7 alloys [Fig. 5(a)]. For systematic control of the alloy composition, we have considered a pseudoternary composition triangle with vertex composition of $\mathrm{Zr},\left(\mathrm{Ti}+\mathrm{Nb}\right.$ ) and $\mathrm{Be}_{17} \mathrm{Cu}_{9} \mathrm{Ni}_{4}$ (composition of the master alloy used for addition of $\mathrm{Be}$ ), as presented in Fig. 6. From the result of EDS analysis of LN14 alloy, the composition of $\beta$ dendrite and glass matrix phases are marked as A and B, respectively, in Fig. 6. As the first step for an alloy design using the pseudoternary composition triangle, the alloy with the 1:1 ratio of dendrite $\left(\mathrm{Ti}_{45.5} \mathrm{Nb}_{42.8} \mathrm{Zr}_{9} \mathrm{Cu}_{2.7}\right)$ :matrix $\left(\mathrm{Ti}_{25.2} \mathrm{Zr}_{27.1} \mathrm{Ni}_{5.7} \mathrm{Cu}_{12.6} \mathrm{Be}_{24.6} \mathrm{Nb}_{4.8}\right)$ compositions of the LN14 alloy (the resulting alloy composition was $\mathrm{Ti}_{35.4} \mathrm{Zr}_{18} \mathrm{Ni}_{2.9} \mathrm{Cu}_{7.7} \mathrm{Be}_{12.3} \mathrm{Nb}_{23.8}$ ) was suction-cast into a 5-mm-diameter rod sample. As shown in Fig. 7(a) the as-cast $\mathrm{Ti}_{35.4} \mathrm{Zr}_{18} \mathrm{Ni}_{2.9} \mathrm{Cu}_{7.7} \mathrm{Be}_{12.3} \mathrm{Nb}_{23.8}$ alloy (will be referred to as DN24 alloy, hereafter) consisted of glass matrix (gray), $\beta$ phase (white), and NbZr phase (black). ${ }^{23}$ The phases were confirmed by XRD analysis in Fig. 7(d). Despite increase of the volume fraction of $\beta$ phase ( $\sim 5 \%$ ) compared to the LN14 alloy, the yield strength increased up to $\sim 1870 \mathrm{MPa}$, but the plastic strain was diminished down to $\sim 11.5 \%$ [Fig. 7(c)]. It is considered that this result is caused by the presence of brittle phase. ${ }^{24,25}$

As the second step for the alloy design procedure, the alloy with reduced $\mathrm{Nb}$ content was prepared to 
prevent the formation of the $\mathrm{NbZr}$ phase, i.e., the $\mathrm{Ti}_{45.2} \mathrm{Zr}_{18} \mathrm{Ni}_{2.9} \mathrm{Cu}_{7.7} \mathrm{Be}_{12.3} \mathrm{Nb}_{14}$ alloy (will be referred to as DN14 alloy, hereafter) was designed by replacing $\mathrm{Nb}$ with $\mathrm{Ti}$ by 10 at. $\%$ in the $\mathrm{Ti}_{35.4} \mathrm{Zr}_{18}$ $\mathrm{Ni}_{2.9} \mathrm{Cu}_{7.7} \mathrm{Be}_{12.3} \mathrm{Nb}_{23.8}$ alloy (DN24 alloy). The microstructure shown in Fig. 7(b) indicates that the as-cast

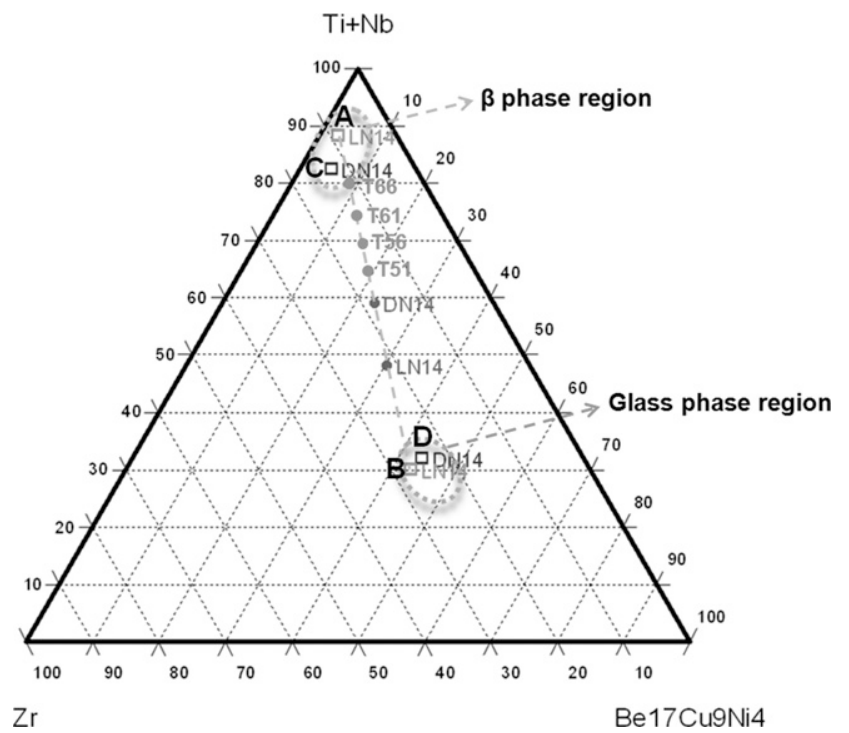

FIG. 6. A pseudoternary composition triangle for $\mathrm{Ti}-\mathrm{Zr}-\mathrm{Be}-\mathrm{Cu}-\mathrm{Ni}-$ $\mathrm{Nb}$ alloy in the present study.
DN14 alloy is composed of $\beta$ dendrite and glass matrix phases without the NbZr phase because of the smaller amount of $\mathrm{Nb}$ content. The XRD pattern in Fig. 7(d) confirms the existence of $\beta$ and glassy phases. As shown in Fig. 7(c), the DN14 alloy exhibited much larger plastic strain of $\sim 24 \%$ than that of the DN24 alloy with a slight decrease of yield strength $(\sim 1600 \mathrm{MPa})$ due to suppression of the $\mathrm{NbZr}$ phase formation. From the result, the DN14 alloy was selected as the alloy composition for design of pseudobinary quasi-equilibrium of $\beta$ and glassy phases. The compositions of $\beta$ dendrite and glass matrix phases in the DN14 alloy were $\mathrm{Ti}_{50.3} \mathrm{Zr}_{12.9} \mathrm{Cu}_{4.7} \mathrm{Nb}_{32}$ and $\mathrm{Ti}_{28} \mathrm{Zr}_{24.3} \mathrm{Ni}_{5.7} \mathrm{Cu}_{13.2} \mathrm{Be}_{24.6} \mathrm{Nb}_{4.1}$, respectively, as listed in Table I. The compositions of $\beta$ and glassy phases are marked as $\mathrm{C}$ and $\mathrm{D}$ in the pseudoternary composition triangle (Fig. 6). Interestingly, it can be noticed that the positions of $\mathrm{A}$ and $\mathrm{C}$, and $\mathrm{B}$ and $\mathrm{D}$, respectively, were close [maximum $\sim 6$ at.\% compositional difference in (Ti $+\mathrm{Nb}$ ) content], indicating that there may be pseudobinary quasi-equilibrium between $\beta$ and glassy phases with the composition range covering $\mathrm{A}(\mathrm{C})$ and $\mathrm{B}(\mathrm{D})$, respectively. ${ }^{14}$ Therefore, using the compositions of $\beta$ and glassy phases, a series of alloys were prepared by selecting four alloy compositions on the line connecting $\beta$ (A position) and glassy (B position) phase compositions in the pseudoternary composition triangle. The composition of four alloys referred to as T51, T56,
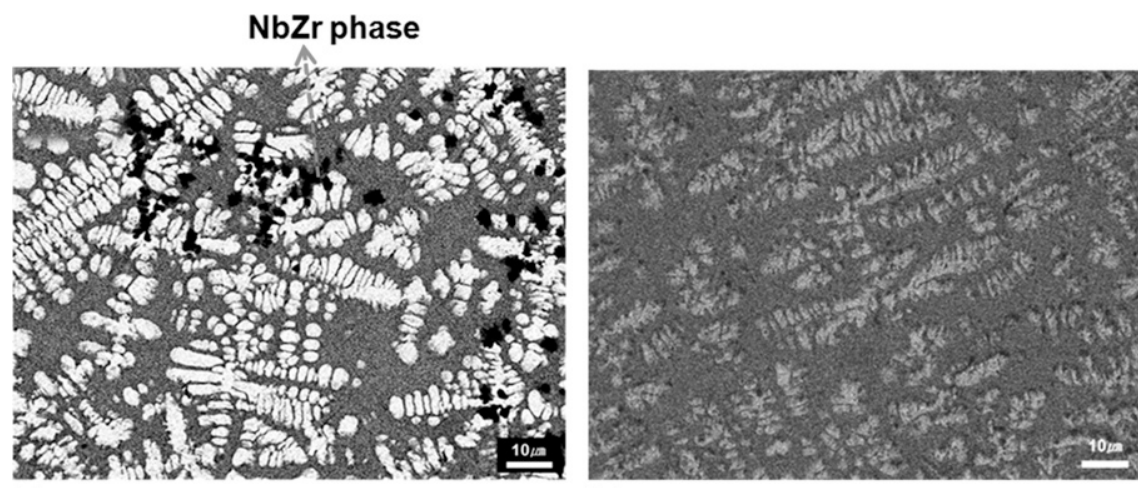

(a)

(b)
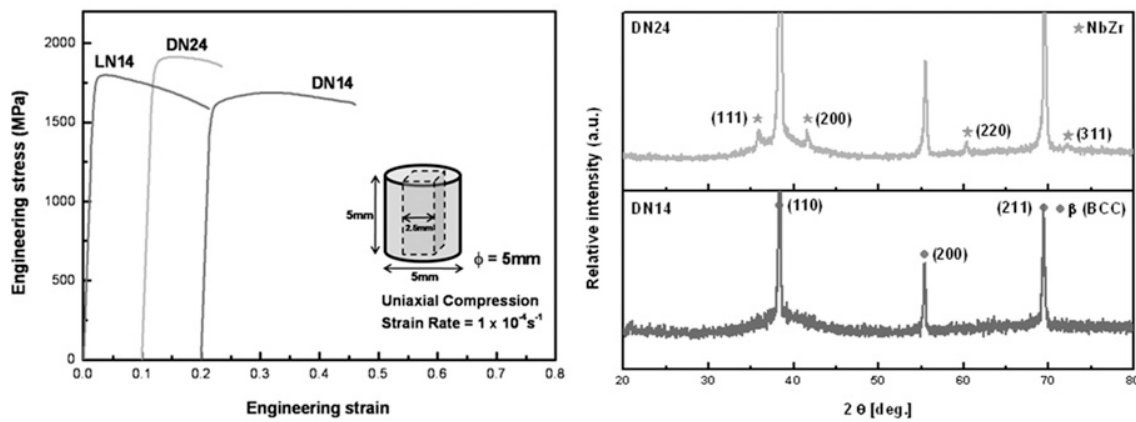

(c)

(d)

FIG. 7. SEM backscattered images of as-cast (a) $\mathrm{Ti}_{35.4} \mathrm{Zr}_{18} \mathrm{Ni}_{2.9} \mathrm{Cu}_{7.7} \mathrm{Be}_{12.3} \mathrm{Nb}_{23.8}$ (DN24) and (b) $\mathrm{Ti}_{45.2} \mathrm{Zr}_{18} \mathrm{Ni}_{2.9} \mathrm{Cu}_{7.7} \mathrm{Be}_{12.3} \mathrm{Nb}_{14}$ (DN14) alloys. (c) Compressive engineering stress-strain curves at room temperature for the machined LN14, DN24, and DN14 specimens. (d) XRD patterns of as-cast DN24 and DN14 rods with a 5 mm diameter. 
TABLE II. Volume fractions of $\beta$ phase and compressive yield strengths of all investigated alloys on the pseudoternary composition triangle.

\begin{tabular}{llcc}
\hline \hline Alloy & \multicolumn{1}{c}{ Composition (at.\%) } & $\mathrm{V}_{\beta}(\%)$ & Yield strength (MPa) \\
\hline LN14 & $\mathrm{Ti}_{34.4} \mathrm{Zr}_{21.5} \mathrm{Nb}_{14} \mathrm{Ni}_{4} \mathrm{Cu}_{8.9} \mathrm{Be}_{17.2}$ & 28 & 1730 \\
DN14 & $\mathrm{Ti}_{45.2} \mathrm{Zr}_{18} \mathrm{Nb}_{14} \mathrm{Ni}_{2.9} \mathrm{Cu}_{7.7} \mathrm{Be}_{12.3}$ & 44 & 1400 \\
T51 & $\mathrm{Ti}_{51} \mathrm{Zr}_{16} \mathrm{Nb}_{14} \mathrm{Ni}_{2.3} \mathrm{Cu}_{6.7} \mathrm{Be}_{10}$ & 68 & 1120 \\
T56 & $\mathrm{Ti}_{56} \mathrm{Zr}_{15} \mathrm{Nb}_{14} \mathrm{Ni}_{1.7} \mathrm{Cu}_{5.8} \mathrm{Be}_{7.5}$ & 72 & 1030 \\
$\mathrm{~T} 61$ & $\mathrm{Ti}_{61} \mathrm{Zr}_{13} \mathrm{Nb}_{14} \mathrm{Ni}_{1.3} \mathrm{Cu}_{5.2} \mathrm{Be}_{5.5}$ & 75 & 920 \\
$\mathrm{~T} 66$ & $\mathrm{Ti}_{66} \mathrm{Zr}_{12} \mathrm{Nb}_{14} \mathrm{Ni}_{0.7} \mathrm{Cu}_{4.4} \mathrm{Be}_{2.9}$ & 96 & 800 \\
\hline \hline
\end{tabular}

T61, and T66 alloys are listed in Table II. Here, Nb content was fixed at 14 at.\% to prevent formation of the $\mathrm{NbZr}$ phase, therefore Ti content increased from 51 at.\% (in T51 alloy) to 66 at.\% (in T66 alloy) as the alloy composition approached the composition of $\beta$ phase. As shown in Fig. 6, the line also penetrates the compositions of the LN14 and DN14 alloys. If LN14 and DN14 alloys are considered together, Ti content varied from 34 to 66 at.\% in the series of alloys from LN14 alloy to T66 alloy, as listed in Table II.

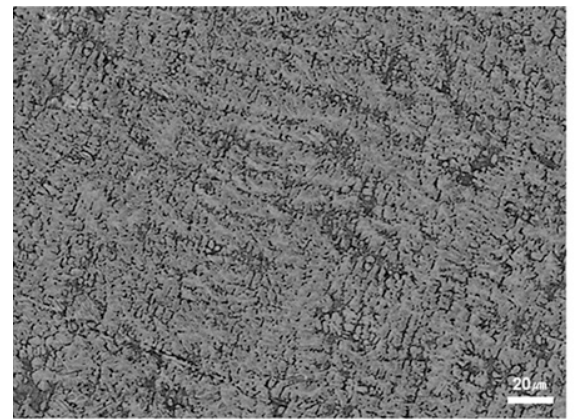

(a)

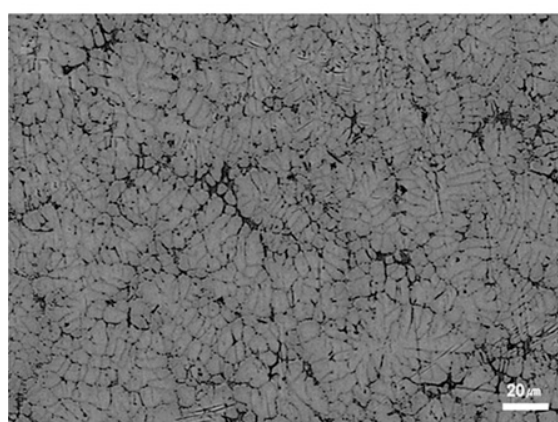

(c)

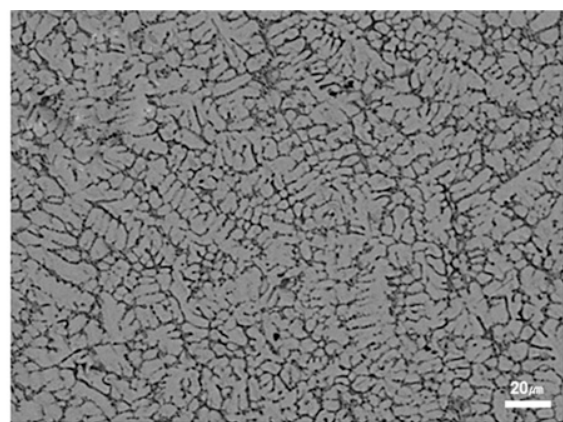

(b)

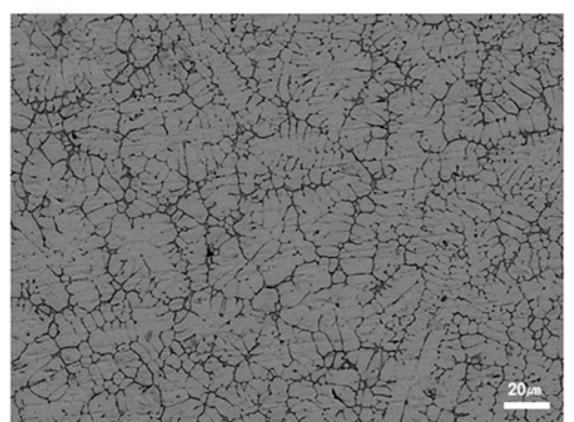

(d)

FIG. 8. SEM backscattered images of the series of alloys from T51 to T66.

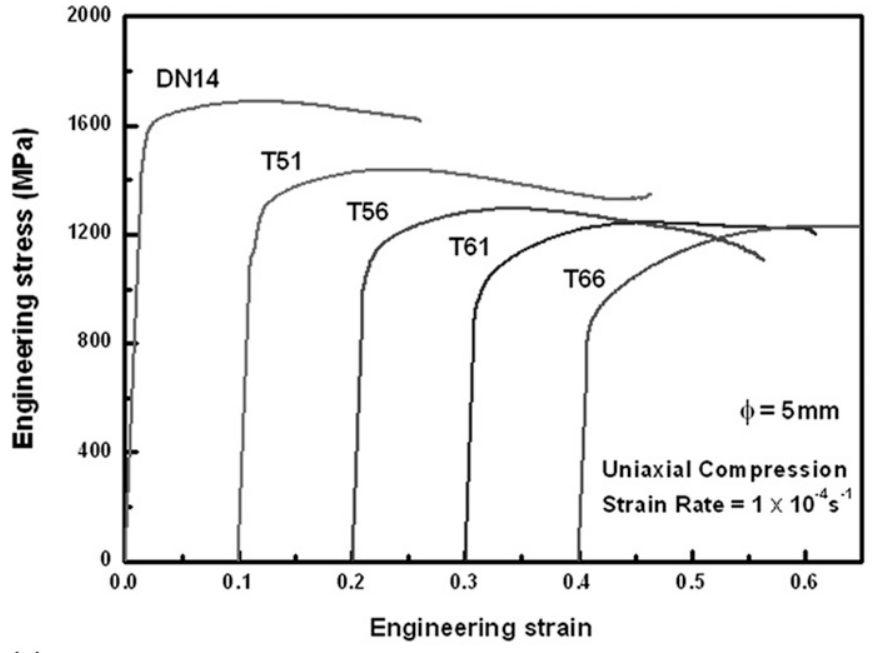

(a)

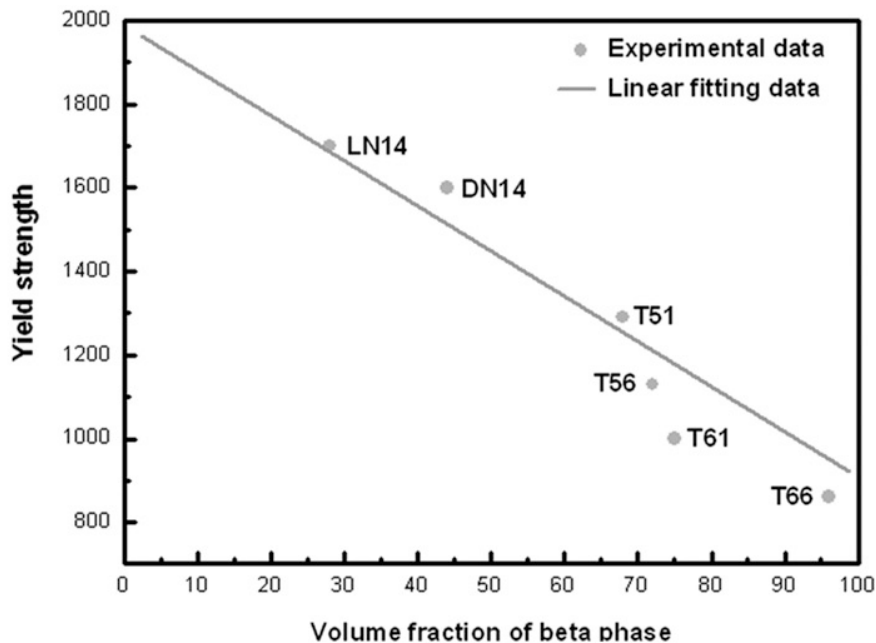

(b)

FIG. 9. (a) The compressive engineering stress-strain curves at room temperature for the machined specimens of the series of alloys from LN14 to T66. (b) Relationship between the volume fraction of $\beta$ phase and the compressive yield strength. 
Figure 8 shows backscattered electron images obtained from T51, T56, T61, and T66 alloys. The phase analysis was conducted by XRD experiments (not shown). The as-cast microstructure of four alloys consisted of the $\beta$-phase dendrite (light contrast) embedded in the glass matrix (dark contrast). As the Ti content increased, the volume fraction of $\beta$ phase also increased, from 28\% in LN14 alloy to $96 \%$ in T66 alloy, as listed in Table II.

Figure 9(a) shows the result of the compression tests obtained from DN14, T51, T56, T61, and T66 alloys. It can be clearly seen that as Ti content increased (as the fraction of the $\beta$ phase increased), the yield strength decreased, but the plastic strain increased significantly. Table II summarizes volume fractions of $\beta$ phase and a compressive test result (yield strength). The total strain of the T51, T56, T61, and T66 samples were over 35\%, therefore the compression test was stopped when the total strain reached $35 \%$. The relation between the compressive yield strength and volume fraction of $\beta$ phase is plotted in Fig. 9(b). LN14 alloy also shows high plasticity in compression test. Therefore, in this study, the composition range of $\beta$ and glassy phases, which are in pseudobinary quasi-equilibrium state can be drawn, enabling the tailoring the volume fraction of the $\beta$ phase embedded in the amorphous matrix, thereby tailoring the mechanical properties of the Ti-rich $\mathrm{Ti}-\mathrm{Zr}-\mathrm{Cu}-\mathrm{Ni}-\mathrm{Nb}-\mathrm{Be}$ system.

\section{CONCLUSIONS}

In this study, we developed a Ti-based bulk metallic glass matrix composite by controlling characteristic and volume fraction of primary phase embedded in the glass matrix. The primary concern was placed on the selection of compositions of Ti-rich $\beta$ phase and glass matrix phase, which are in pseudobinary quasi-equilibrium. By a careful alloy design procedure, the composition of $\beta$ glass phases in pseudobinary quasi-equilibrium to each other has been properly selected, therefore the mechanical properties can be tailored by selecting the alloy compositions between the composition of $\beta$ and glassy phases. The relation between the compressive yield strength and volume fraction of $\beta$ phase is well correlated using the rule of mixtures.

\section{ACKNOWLEDGMENTS}

This work was supported by the Global Research Laboratory Program of Korea Ministry of Science and Technology and the Center for Advanced Materials Processing (CAMP) of the 21st Century Frontier R\&D Program funded by the Korea Ministry of Knowledge Economy. K.R. Lim acknowledges the support from the Second Stage of Brain Korea 21 Project.

\section{REFERENCES}

1. C.J. Byrne and M. Eldrup: Bulk metallic glasses. Science 321, 502 (2008).

2. F.X. Qin, X.M. Wang, G.Q. Xie, and A. Inoue: Distinct plastic strain of $\mathrm{Ni}$-free $\mathrm{Ti}-\mathrm{Zr}-\mathrm{Cu}-\mathrm{Pd}-\mathrm{Nb}$ bulk metallic glasses with potential for biomedical applications. Intermetallics 16, 1026 (2008).

3. M.L. Lee, Y. Li, and C.A. Schuh: Effect of a controlled volume fraction of dendritic phases on tensile and compressive ductility in La-based metallic glass matrix composites. Acta Mater. 52, 4121 (2004).

4. E.S. Park and D.H. Kim: Design of bulk metallic glasses with high glass forming ability and enhancement of plasticity in metallic glass matrix composites: A review. Met. Mater. Int. 11, 19 (2005).

5. F. Szuecs, C.P. Kim, and W.L. Johnson: Mechanical properties of $\mathrm{Zr}_{56.2} \mathrm{Ti}_{13.8} \mathrm{Nb}_{5.0} \mathrm{Cu}_{6.9} \mathrm{Ni}_{5.6} \mathrm{Be}_{12.5}$ ductile phase reinforced bulk metallic glass composite. Acta Mater. 49, 1507 (2001).

6. E. Pekarskaya, C.P. Kim, and W.L. Johnson: In situ transmission electron microscopy studies of shear bands in a bulk metallic glass based composite. J. Mater. Res. 16, 9 (2001).

7. C.C. Hays, C.P. Kim, and W.L. Johnson: Improved mechanical behavior of bulk metallic glasses containing in situ formed ductile phase dendrite dispersions. Mater. Sci.Eng., A 304-306, 650 (2001).

8. H.J. Jun, K.S. Lee, C.P. Kim, and Y.W. Chang: Temperature effects on mechanical properties, deformation behavior and formability of $\mathrm{Zr}-\mathrm{Ti}-\mathrm{Cu}-\mathrm{Ni}-\mathrm{Be}-\mathrm{Nb}$ bulk metallic glass composite. Met. Mater. Int. 14, 297 (2008)

9. Y.L. Huang, A. Bracchi, T. Niermann, M. Seibt, D. Danilov, B. Nestler, and S. Schneider: Dendritic microstructure in the metallic glass matrix composite $\mathrm{Zr}_{56} \mathrm{Ti}_{14} \mathrm{Nb}_{5} \mathrm{Cu}_{7} \mathrm{Ni}_{6} \mathrm{Be}_{12}$. Scr. Mater. 53, 93 (2005).

10. D.C. Hofmann, J.Y. Suh, A. Wiest, G. Duan, M.L. Lind, M.D. Demetriou, and W.L. Johnson: Designing metallic glass matrix composites with high toughness and tensile ductility. Nature 451, 1085 (2008).

11. J.M. Park, D.H. Kim, K.B. Kim, E. Fleury, M.H. Lee, W.T. Kim, and J. Eckert: Enhancement of plasticity in Ti-rich $\mathrm{Ti}-\mathrm{Zr}-\mathrm{Be}-\mathrm{Cu}-$ $\mathrm{Ni}-\mathrm{Ta}$ bulk glassy alloy via introducing the structural inhomogeneity. J. Mater. Res. 23, 2984 (2008).

12. J.M. Park, H.J. Chang, K.H. Han, W.T. Kim, and D.H. Kim: Enhancement of plasticity in Ti-rich $\mathrm{Ti}-\mathrm{Zr}-\mathrm{Be}-\mathrm{Cu}-\mathrm{Ni}$ bulk metallic glasses. Scr. Mater. 53, 1 (2005).

13. F. Guo, H.J. Wang, S.J. Poon, and G.J. Shiflet: Ductile titaniumbased glassy alloy ingots. Appl. Phvs. Lett. 86, 091907 (2005)

14. S.Y. Lee, C.P. Kim, J.D. Almer, U. Lienert, E. Ustundag, and W.L. Johnson: Pseudo-binary phase diagram for Zr-based in situ $\beta$ phase composites. J. Mater. Res. 22, 2 (2007).

15. L. Lin, L. Delaey, O. Van Der Biest, and P. Wollants: Calculation of isothermal sections of three ternary $\mathrm{Ti}-\mathrm{Zr}-\mathrm{X}$ systems. $\underline{\mathrm{Scr}}$. Mater. 34, 1411 (1996).

16. M.Y. He and J.W. Hutchinson: Crack deflection at an interface between dissimilar elastic materials. Int. J. Solids Struct. 25, 1053 (1989).

17. H. Ikehata, N. Nagasako, T. Furuta, A. Fukumoto, K. Miwa, and T. Saito: First-principles calculations for development of low elastic modulus Ti alloys. Phvs. Rev. B 70, 174113 (2004).

18. J.N. Mei, J.S. Li, H.C. Kou, J.L. Soubeyroux, H.Z. Fu, and L. Zhou: Formation of $\mathrm{Ti}-\mathrm{Zr}-\mathrm{Ni}-\mathrm{Cu}-\mathrm{Be}-\mathrm{Nb}$ bulk metallic glasses. J. Allovs Compd. 467, 1 (2009).

19. Y. Mantani, Y. Takemoto, M. Hida, A. Sakakibara, and M. Tajima: Phase transformation of $\alpha^{\prime \prime}$ martensite structure by aging in Ti-8 mass\%Mo alloy. Mater. Trans. 45(5), 1629 (2004).

20. D.H. Ping, Y. Yamabe-Mitarai, C.Y. Cui, F.X. Yin, and M.A. Choudhry: Stress-induced $\alpha^{\prime \prime}$ martensitic (110) twinning in B-Ti alloys. Appl. Phys. Lett. 9, 1519113 (2008). 
21. A.T. Balcerzak and S.L. Sass: The formation of the $\omega$ phase in Ti-Nb alloys. Metall. Trans. 3, 1601 (1972).

22. H. Xing and J. Sun: Mechanical twinning and omega transition by $\langle 111\rangle\{112\}$ shear in a metastable $\beta$ titanium alloy. Appl. Phvs. Lett. 93, 031908 (2008).

23. O. Jin and B.X. Liu: Non-equilibrium solid phases formed by ion mixing in the $\mathrm{Zr}-\mathrm{Nb}$ system with positive heat of formation. J.Phvs. Condens. Matter 6, L39 (1994)
24. G. He, J. Eckert, W. Löser, and M. Hagiwara: Composition dependence of the microstructure and the mechanical properties of nano/ultrafine-structured $\mathrm{Ti}-\mathrm{Cu}-\mathrm{Ni}-\mathrm{Sn}-\mathrm{Nb}$ alloys. Acta Mater. 52. 3035 (2004).

25. Y.F. Sun, S.K. Guan, B.C. Wei, Y.R. Wang, and C.H. Shek: Brittleness of Zr-based bulk metallic glass matrix composites containing ductile dendritic phase. Mater. Sci. Eng.. A 406, 57 $\underline{(2005)}$. 